\title{
ВMJ Global Health Spiritual issues of people living and dying with advanced heart failure in Kenya: a qualitative serial interview study
}

\author{
Kellen N Kimani, ${ }^{1}$ Scott A Murray, ${ }^{2}$ Liz Grant ${ }^{3}$
}

To cite: Kimani KN, Murray SA, Grant L. Spiritual issues of people living and dying with advanced heart failure in Kenya: a qualitative serial interview study. BMJ Global Health 2016;1: e000077. doi:10.1136/ bmjgh-2016-000077

- Additional material is published online only. To view please visit the journal online (http://dx.doi.org/10. 1136/bmjgh-2016-000077).

Received 27 April 2016 Revised 26 September 2016 Accepted 27 September 2016

\section{(a) CrossMark}

${ }^{1}$ School of Public Health, University of Nairobi, Nairobi, Kenya

${ }^{2}$ Primary Palliative Care Research Group, The Usher Institute, University of Edinburgh, Edinburgh, UK ${ }^{3}$ Global Health Academy, University of Edinburgh, Edinburgh, UK

Correspondence to Dr Kellen N Kimani; K.N.Kimani@sms.ed.ac.uk

\section{ABSTRACT}

Background: Exploring patients' spiritual issues is vital for informing holistic care. The spiritual concerns of patients living and dying with advanced heart failure in sub-Saharan Africa remains unknown. Our aim was to describe spiritual issues in the context of the lived experiences of patients with heart failure in Kenya.

Methods: We purposively recruited 18 patients admitted with advanced heart failure at a rural district hospital in Kenya. We conducted serial in-depth interviews with patients at 0, 3 and 6 months after recruitment. We conducted bereavement interviews with their carers. Interviews were recorded, transcribed into English and analysed using a thematic approach, assisted by Nvivo software package.

Results: Patients expressed traditional and Christian spiritual beliefs in response to their illness. At diagnosis, some patients felt their illness had occurred because they had wronged God, while others felt betrayed by God. Some expressed comfort from God and optimism believing that God was in control and would heal their illness. During acute episodes patients questioned whether witchcraft or curses caused their illness. Younger patients experienced more spiritual distress. Although church fellowship generally offered spiritual and social support, some patients felt let down by the church which they perceived to favour those who offered more tithes.

Conclusions: This is the first study to explore the spiritual issues of people living with advanced heart failure in Kenya. Understanding patients' spiritual concerns is important for developing evidence-based patient-centred holistic care to promote multidimensional well-being.

\section{INTRODUCTION}

The notion that spirituality influences how people experience disease is not new. Throughout human history, spirituality has strongly been associated with health and illness. For example, in prehistoric times, diseases were understood to be caused by supernatural forces and were treated by applying natural and spiritual practices. ${ }^{1}$ In modern

\section{Key questions}

What is already known about this topic?

- Spirituality influences how people experience illness.

- Diagnosis of a life-threatening illness may trigger existential angst.

- Spiritual distress may trigger physical and emotional distress and lead to increased health service use.

What are the new findings?

- This is the first longitudinal study to explore spiritual concerns of patients with heart failure in sub-Saharan Africa.

- Patients' spirituality offered comfort but was also a source of distress.

- Younger patients experience considerable spiritual distress.

Recommendations for policy

- This study highlights the need for patientcentred holistic care to identify spiritual concerns contributing to distress.

- Spiritual distress may lead to poorer health outcomes for patients.

- Holistic care may improve patients' wellbeing, reduce healthcare usage and curtail the vicious cycle of poverty associated with chronic diseases in this setting.

times, the importance of spirituality in health is evident from its inclusion in numerous clinical measures ${ }^{2}$ including those that assess quality of life ${ }^{3}$ Furthermore, spirituality is also as an important component of holistic approaches to care $^{4}$ including palliative care. $^{5}$

Receiving a diagnosis of a life-threatening illness can be a traumatic experience. Questions such as why is this happening? or why $m e$ ? often reveal existential angst as people attempt to make meaning of their diagnosis and the reality of death. ${ }^{6}$ Previous studies on the experience of living with heart 
failure $(\mathrm{HF})$ conducted in the UK reveal that patients experience multidimensional distress throughout the illness trajectory. As physical symptoms deteriorate patients suffer a decline in psychosocial and spiritual well-being. Unpredictable acute episodes and the risk of sudden death mean that patients may be unprepared for worsening symptoms which may heighten their distress. ${ }^{78}$ Poor communication from health professionals and a lack of understanding of their illness may add to their suffering. ${ }^{9} 10$

As patients struggle to find meaning they may rely on their spirituality to make sense of their experience. Westlake and Dracup ${ }^{11}$ identified ways in which spirituality may help people with HF adjust to their illness. By searching for meaning in their experience, patients may regain hope and renewed optimism. Such positive spiritual responses have been associated with better health outcomes as patients experience fewer symptoms of depression, ${ }^{12}$ enhanced quality of life ${ }^{13}$ and better health practices ${ }^{14}$ such as improved adherence to treatment. ${ }^{15}$

Sub-Sahara Africa (SSA) now faces a burgeoning epidemic from non-communicable diseases. ${ }^{16}$ Although countries in North America and Europe may bear a greater disease burden, low-resource settings experience higher mortality rates. While the extent of the disease burden is yet to be quantified in SSA, hospital surveys estimate that $\mathrm{HF}$ accounts for $9-15 \%$ of admissions. ${ }^{17}$ The unpredictable and long-term nature of these illnesses, together with its potential for significant psychosocial and spiritual distress, is likely to place a significant strain on the existing fragile health systems. ${ }^{16} 18$

In order to develop holistic services that can respond to patients' dynamic needs, it is vital to explore how their spirituality influences their illness experience. Unmet spiritual needs may lead more to physical, psychological and spiritual distress which results in more health service use. ${ }^{19}$ Given the highly spiritual nature of communities in SSA and the considerable role of spirituality in wellbeing, it is crucial to explore how this influences the experience of living with HF in SSA. In this region, literature exists describing the role of spirituality for patients with chronic diseases such as cancer and HIV $;{ }^{20-22}$ however, similar evidence from people living with $\mathrm{HF}$ remains scarce. This paper aims to fill this gap by reporting the spiritual issues of patients with HF in Kenya.

We acknowledge that spirituality is a complex phenomenon and definitions vary. ${ }^{23}$ In this paper, we embrace a broad definition: "spirituality is the aspect of humanity that refers to the way individuals seek and express meaning and purpose and the way they experience their connectedness to the moment, to self, to others, to nature, and to the significant or sacred". ${ }^{24}$

\section{METHODS}

\section{Study design}

We conducted a longitudinal qualitative study using serial in-depth interviews to explore patients' lived multidimensional experiences. This methodology is useful for capturing dynamic needs and preferences along the course of illness. Given the sensitive nature of patients' accounts, longitudinal techniques allowed time for trusting relationships to develop between the participants and researchers facilitating the exploration of these sensitive issues. ${ }^{25}{ }^{26}$ Similar methods have been used to explore the spiritual concerns of patients living with cancer and non-malignant illnesses. ${ }^{7} 19$

Interviews were conducted at three monthly intervals up to a maximum of 6 months. However, this was flexible and dependent on a patient's health status or the occurrence of an event, such as a hospital admission triggering an earlier or later interview. KNK, a female Kenyan public health doctor conversant in the local vernacular as well as Kiswahili and English conducted the interviews. Interviews took place in hospital wards or at the patient's home and lasted 25-125 min. Patients were contacted on phone monthly to maintain contact and schedule subsequent interviews. Changes in their condition were recorded. Written consent was obtained before starting the first interview and confirmed verbally prior to subsequent interviews.

A topic guide was used to steer interviews. It explored patients' subjective physical, social, psychological and spiritual experiences including their experiences and expectations of care (see online supplementary file). Interviews were conducted in local language Kiswahili or English. Interviews were audio recorded in local language and transcribed into English by KNK with the assistance of an experienced transcriptionist. Field notes were written after each interview to record the observations made while interviewing.

\section{Methodological orientation}

This research was underpinned by a critical realist theoretical orientation. Critical realism is a philosophy between relativist and objectivist theoretical perspectives. It claims to be a realist ontology and a constructivist epistemology. Reality is viewed as being external and independent but individually constructed. It underpins several analytic approaches including thematic analysis. $^{27-29}$

\section{Study participants}

Patients were purposively recruited from a county hospital (previously a district hospital) serving a predominantly rural population in Kenya. Hospital doctors and nurses identified potential patient participants on the ward and informed them about the study. Patients were sampled to reflect the local epidemiology and sociodemographic characteristics of people with $\mathrm{HF}$ in this setting. This was guided by local statistics, hospital data and published literature. ${ }^{30}$ We also asked patients to identify a carer for bereavement interviewing. In some cases we anticipated that patients would not wish to identify a carer. In such instances, we respected the patient's preference. 
Forty patients admitted with a diagnosis of advanced HF classified as New York Heart Association Grade III/ IV were found suitable by their clinician and approached for recruitment. Of these, 18 agreed to take part and 22 declined. Eighteen carers were also identified by patients for possible bereavement interviewing. We excluded patients with cognitive impairment, with a primary diagnosis of another advanced life-limiting illness (such as cancer) requiring most care, and those living beyond $35 \mathrm{~km}$ from the recruiting facility. Our sample size was informed by previous research in the experiences of patients with advanced HF in the UK suggesting that serial interviews with 20-25 participants would generate ample data to approach saturation and answer our research questions, ${ }^{31}$ guidelines from ethics committees and resources available to successfully complete the study. ${ }^{32}$

\section{Analysis}

Transcripts and field notes were analysed using the Braun and Clarke ${ }^{33}$ approach to thematic analysis. The analysis included an initial data familiarisation phase followed by code generation to identify patterns. Codes were organised to form themes portraying participants' experiences with an ongoing review of themes to ensure data within themes were coherent and variations between themes were distinguishable. The analysis was iterative and occurred throughout the research process. $^{34}$ Regular multidisciplinary advisory group meetings (with LG, KNK, SAM) were held to review the emerging codes, themes and assess for data saturation. In addition, a research journal was kept to maintain reflexivity. Data management was assisted by qualitative package Nvivo. The COREQ checklist guided reporting. ${ }^{35}$

\section{RESULTS}

A total of 18 patients ( 10 women; 8 men) took part in this study. Five patients died and four were untraceable by the end of the study. Two interviews were held with bereaved carers. All patients ascribed their religious affiliation as Christian and reported a belief in God with 15 regularly attending a church service. Attempts were made to recruit participants from other religious groups, but the predominance of Christianity in this community prevented this. All participants were Kenyans, the majority being Kikuyu.

Table 1 summarises participants.

Throughout their illness, patients experienced considerable multidimensional distress. Their physical decline was interrupted by periods of acute exacerbations. Physical symptoms such as breathlessness, fatigue, ankle swelling, exercise intolerance and insomnia were common. Most were poorly informed as they did not understand their diagnosis, treatment regimen or how to plan for the future. The cost of care was a significant burden for patients which at times resulted in significant distress. Within this context spiritual issues were identified.

\section{Spiritual issues expressed at the time of diagnosis}

Although most patients knew they had a 'heart problem', they were not aware of the significance of their diagnosis. They felt vulnerable as they were confronted by an unfamiliar illness. This often caused anxiety as patients questioned the origin of their illness. At this time, some patients derived comfort from their belief in an omniscient God.

Where is this illness from? We don't have this illness in our family....only God knows where it's from (Patient 6, woman, 60, 1st interview).

Other patients considered whether their illness was caused by a 'curse' from an estranged family member or a friend. These thoughts brought about feelings of victimisation particularly during periods of acute physical deterioration. However, once the symptoms had subsided with treatment these thoughts were ameliorated as patients felt confident that their improvement was proof that God had control over their illness.

Before I wonder whether if this (illness) is a curse because it (the illness) wasn't like this before.... but I stopped thinking about those things. It's God who knows and if it was a curse I would have died a while ago. It's only a disease and it will come to an end (Patient 12, woman, 19, 1st interview)

Most patients believed that their illness like other life events, were orchestrated by God. In their suffering, some patients felt it was inappropriate to express distress as this would reveal their distrust in God.

I don't worry about the concerns of this world... God does as he wills. I've decided never ask to ask God why he made me sick....he also takes those who are not ill. It's better to be ill as the Lord would wish. This body isn't mine. My body is his, my heart is his. God will do as he wills. The best you can do is be patient and wait on him (Patient 14, woman, 60, 1st interview)

For some patients diagnosis led to a questioning of belief in God.

The other concerns I have are religious....we all don't know where we are going to go. I've been a religious person but not that committed. Maybe I should believe in salvation....in case anything happens, I have nothing to lose....But if I choose not to believe I won't be sure of my fate. But with salvation I will have nothing to worry about (Participant 7, man, 50, 1st interview)

\section{Spiritual issues experienced during the time of treatment}

For some, the second interviews revealed that once acute symptoms had subsided they felt confident in their hope for a full recovery. A reduction in 


\begin{tabular}{|c|c|c|c|c|c|c|c|c|c|}
\hline \multirow[b]{2}{*}{$\begin{array}{l}\text { Patient } \\
\text { number }\end{array}$} & \multirow[b]{2}{*}{$\begin{array}{l}\text { Gender, } \\
\text { Age }\end{array}$} & \multirow[b]{2}{*}{$\begin{array}{l}\text { Aetiology of } \\
\text { heart failure }\end{array}$} & \multirow[b]{2}{*}{$\begin{array}{l}\text { NYHA } \\
\text { class }\end{array}$} & \multicolumn{3}{|c|}{ Interviews } & \multirow{2}{*}{$\begin{array}{l}\text { Duration } \\
\text { in study } \\
\text { (months) }\end{array}$} & \multirow{2}{*}{$\begin{array}{l}\text { Alive or } \\
\text { dead at end } \\
\text { of study }\end{array}$} & \multirow[b]{2}{*}{$\begin{array}{l}\text { Bereavement } \\
\text { interviews }\end{array}$} \\
\hline & & & & T1 & T2 & T3 & & & \\
\hline 1 & $\begin{array}{l}\text { Female, } \\
57\end{array}$ & $\begin{array}{l}\text { Hypertensive } \\
\text { heart disease }\end{array}$ & III & $P$ & $\mathrm{P}$ & $\mathrm{P}$ & 6 & Alive & \\
\hline 2 & $\begin{array}{l}\text { Female, } \\
35\end{array}$ & $\begin{array}{l}\text { Hypertensive } \\
\text { heart disease }\end{array}$ & IV & $\mathrm{P}$ & $\mathrm{P}$ & $P \& C$ & 6 & Alive & \\
\hline 3 & Male, 65 & $\begin{array}{l}\text { Dilated } \\
\text { cardiomyopathy }\end{array}$ & IV & $\mathrm{P}$ & $\mathrm{P}$ & $\mathrm{P}$ & 6 & Alive & \\
\hline 4 & Male, 75 & $\begin{array}{l}\text { Right-sided heart } \\
\text { failure (from } \\
\text { COPD) }\end{array}$ & III & $P \& C$ & $P \& C$ & $P \& C$ & 6 & Alive & \\
\hline 6 & $\begin{array}{l}\text { Female, } \\
60\end{array}$ & $\begin{array}{l}\text { Hypertensive } \\
\text { heart disease }\end{array}$ & IV & $P \& C$ & $\dagger$ & & 2 & Dead & $\checkmark$ \\
\hline 7 & Male, 50 & $\begin{array}{l}\text { Dilated } \\
\text { cardiomyopathy }\end{array}$ & III & $\mathrm{P}$ & $\mathrm{P}$ & $\mathrm{P}$ & 6 & Alive & \\
\hline 8 & $\begin{array}{l}\text { Female, } \\
50\end{array}$ & $\begin{array}{l}\text { Hypertensive } \\
\text { heart disease }\end{array}$ & III & $\mathrm{P}$ & $P \& C$ & $\mathrm{P}$ & 6 & Alive & \\
\hline 9 & Male, 38 & $\begin{array}{l}\text { Hypertensive } \\
\text { heart disease }\end{array}$ & III & $\mathrm{P}$ & Untrac & eable & 1 & Not known & \\
\hline 10 & Male, 45 & $\begin{array}{l}\text { Right-sided heart } \\
\text { failure (from } \\
\text { COPD) }\end{array}$ & IV & $\mathrm{P}$ & $\mathrm{P}$ & $\dagger$ & 5 & Dead & $\begin{array}{l}X \text {-carer lived } \\
\text { beyond } 35 \mathrm{~km} \\
\text { from recruiting } \\
\text { hospital }\end{array}$ \\
\hline 14 & $\begin{array}{l}\text { Female, } \\
60\end{array}$ & $\begin{array}{l}\text { Hypertensive } \\
\text { heart disease }\end{array}$ & IV & $P \& C$ & $\dagger$ & & 1 & Dead & $\checkmark$ \\
\hline 15 & $\begin{array}{l}\text { Female, } \\
31\end{array}$ & $\begin{array}{l}\text { Dilated } \\
\text { cardiomyopathy }\end{array}$ & III & $\mathrm{P}$ & Untrac & eable & 1 & Not known & \\
\hline 16 & $\begin{array}{l}\text { Female, } \\
33\end{array}$ & $\begin{array}{l}\text { Hypertensive } \\
\text { heart disease }\end{array}$ & III & $\mathrm{P}$ & $\mathrm{P}$ & $\mathrm{P}$ & 6 & Alive & \\
\hline 17 & $\begin{array}{l}\text { Female, } \\
50\end{array}$ & $\begin{array}{l}\text { Hypertensive } \\
\text { heart disease }\end{array}$ & III & $\mathrm{P}$ & $\mathrm{P}$ & Untraceable & 5 & Not known & \\
\hline 18 & Male, 36 & $\begin{array}{l}\text { Right-sided heart } \\
\text { failure (from } \\
\text { COPD) }\end{array}$ & IV & $\mathrm{P}$ & Untrac & eable & 1 & Not known & \\
\hline
\end{tabular}

†Death.

C, Carer; COPD, chronic obstructive pulmonary disease; NYHA, New York Heart Association; P, Patient; T1, 1st interview; T2, 2nd interview; T3, 3rd interview.

breathlessness and symptoms such as fatigue and ankle swelling were interpreted as signs of their illness abating due to God's intervention. However, while hoping to recover, many patients also resigned their fate to the will of God. This acceptance was based on the belief that God controlled life and death. A few patients illustrated this conviction by describing how death was not limited to those who are ill.

I don't worry...God knows how long I will live....I leave it to him. You know, someone in good health can die before someone who is ill (Patient 11, 50, woman, 2nd interview) 
Patients whose symptoms persisted despite treatment expressed disappointment as they expected to recover. These feelings were compounded by those of guilt as they felt they had wronged God and that he had abandoned them in their time of need. In the absence of information, these feelings of guilt and disappointment exacerbated their distress

What have I done against you God? Haven't I lived my life as you expect me to? I have 'pressure', 'sugar' (diabetes), kidney and heart problems. Why should I be the only one to have these problems? Even after asking this, there is no answer. These illnesses are more than I can handle (Patient 1, 57, woman, 1st interview)

These feelings of guilt and disappointment were heightened especially in patients whose condition deteriorated requiring repeat admissions. In particular, younger patients experienced greater distress as they felt their illness had limited their ability to work and provide for their families. Additional challenges from unaffordable treatment and declining social support deepened their despair. One orphaned young man, who had made several attempts to end his life, told of his desire for God to end his suffering.

Instead of suffering and I'm not getting better, I'd pray to God to take me away. I don't have a job and I can't afford my drugs ...I pray to God to take away this problem....to shorten it rather than I continue to suffer (Patient 5, 31, man, 2nd interview)

And yet the powerfulness of the sense of God's ownership of life and the spiritual value of life enabled him to hold a counter narrative to his despair.

I still have hope because being alive everyday while in hospital is a blessing. A lot of things that happen in the hospital are shocking.... but when I see a new day, I thank God (Patient 5, 31, man, 2nd interview)

Feelings of deep despair led to patients simultaneously resigning their fate to God, and gained comfort in the belief that while their problems were insurmountable God was in control of life events. For some being alive in spite of severe illness meant that life still had purpose. There was a hopefulness in the peace and purpose they experienced in the face of deteriorating health.

God has a reason for everything. Even though it's a struggle to get to the hospital...I thank God for the help I receive (Patient 2, 35, woman, 2nd interview)

In these times of distress, the church was often viewed as a place of solace. The majority of patients described feeling a sense of tranquillity as they felt they were in the presence of God. Additionally, fellow church members offered support by sharing their experiences. However, a few patients described feeling abandoned by the church as it failed to understand the issues they were going through.

Once church members found out I was sick they abandoned me. My senior pastor discouraged me to go to church. No one wants to be close to you when you have problems (Patient 16, woman, 33, 2nd interview)

Patients believed that illness created different dimensions of separation in some church communities. A few described discrimination and partisanship linked to wellness and prosperity.

Nowadays the church is not helpful. If you don't offer tithe as expected no one will know you. You see, I don't tithe all the time because I don't have money. I noticed that when someone tithes more they plan to visit them. But I've been admitted here for almost a month and no one has prayed for me. There is a lot of discrimination (Patient 2, woman, 35, 2nd interview)

\section{Spiritual issues as patients approached death}

Most patients found it difficult to speak openly about death as they believed only God had authority over its timing.

There are those who are not sick but die from other causes. Yet, I'm ill and I'm still alive.....I take my life as is and pray to God (Patient 13, man, 60, 2nd interview)

For some it was easier to talk indirectly about death by sharing their future plans. One elderly man shared how he had planned for his children to inherit his property, a sign that he was willing to 'let go' and had come to terms with dying.

I have already made arrangements. Every child has a share of the land which they will get when I die (Patient 4, man, 75, 3rd interview)

Other patients responded by spending their last days in prayer asking God for forgiveness for past grievances. Their physical deterioration coupled with financial exhaustion from the cost of care and resultant tensions in social relationship appeared to aggravate patients' suffering. In this state of anxiety, patients felt let down by God and wondered if they had offended him.

\section{Interviewer: Did she speak about why this was happening?}

Carer: She would ask: 'Did I offend God?' She prayed a lot. She would pray day and night and ask God for forgiveness

(Carer for patient 14, woman, 60; bereavement interview)

Despite deteriorating health, some patients in their third interviews remained hopeful that a cure was still possible. They were hopeful that this would prove that 
God had healed them. Patients were looking forward to sharing their experience with others to encourage and offer hope. For instance, 2 days prior to her death, a young female participant expressed her eagerness to share her illness journey as testimony of her belief in God's power to heal.

This illness is like a testimony. I'll tell people about my experience with this illness and let them know that it's God who sustains me. I was once in the intensive care unit and on oxygen and I got better... I will share my testimony (Patient 2, woman, 35, 3rd interview)

\section{DISCUSSION}

Until recently, the multiple dimensions of the experiences of patients with HF in SSA were not described. ${ }^{17} 3637$ This paper illustrates ways in which spirituality influences the experiences of people with $\mathrm{HF}$ in Kenya. Spiritual distress was significant at diagnosis, during periods of acute deterioration and in the last days of life. This was often aggravated by the lack of information about their illness. Younger people were less able to cope with a loss of identity and independence. Patients rarely spoke about death as they felt that this was under God's authority although some had made plans for the future. Patients often relied on their belief in God to make meaning of their experience. Although this helped patients to cope, it at times contributed to their suffering as they struggled to reconcile their experience with a belief in a benevolent God. The church offered comfort for some but was also a source of distress.

Our results are comparable with similar longitudinal studies that show that patients experience multiple dimensions of distress. ${ }^{78}$ In the UK, Murray et $a l^{8}$ found that in people with HF spiritual well-being declines as physical symptoms deteriorate particularly during periods of acute exacerbations. Patients struggle to find meaning with thoughts of dying triggering existential angst as patients question divine indifference at the end of life. ${ }^{38}$ People with HF may experience more prolonged distress and uncertainty compared with those with cancer as their persistent and fluctuating physical symptoms creates uncertainty. ${ }^{39}$

Although these results are similar to those of our study, some findings are unique. We found that younger people experienced greater spiritual distress. Their expectation of remaining physically able to work as well as the societal pressures to provide for their families increased their anxiety. These patients have more difficulties in facing changes in their identity and increasing dependence. ${ }^{40}$ Our findings reveal that people with $\mathrm{HF}$ in Kenya, draw on their spiritual beliefs to cope with their illness. These beliefs possibly stem from traditional religion in which God is regarded as orchestrator of life and death. ${ }^{41}$ These beliefs are further reinforced by a Christian world view. Although these beliefs have been viewed as fatalistic, ${ }^{19}$ they are a source of comfort $^{42}$ but may also reflect a lack of information or a reflection of their deep hope for a cure. ${ }^{43}$ Most of our sample expressed a Christian faith and turned to the church for solace. However, some patients felt rejected by the church's lack of support, especially those churches that appeared to assist more those who contributed most financially, exacerbated a sense of isolation among some.

\section{Implications for practice}

Spiritual issues are often a source of unmet spiritual needs which has been found in the UK to increase physical and emotional distress and lead to greater health service use. ${ }^{19}$ We found that patients relied on their personal resources such as upholding their spiritual beliefs and practices, praying and attending religious services. ${ }^{19}$ While these resources offered comfort they were sometimes a source of distress.

As countries in SSA develop services for patients with chronic diseases, it is vital to acknowledge the significant role of spiritual issues in patients' illnesses. These issues have the potential to trigger deterioration in patients' symptoms, increase need for health services, escalate financial costs for families and contribute to a vicious cycle of poverty. ${ }^{44}$ This presents further significant consequences for socioeconomic development as HF occurs predominantly in those who are economically active in this region. ${ }^{17}$ In addition, spiritual support for those who are ill may be declining in the face of an emerging 'health and wealth' theology. ${ }^{45}$

Previous studies have suggested that a patient-centred approach aimed at meeting holistic needs may be beneficial to people with HF. This approach would aim to care for patients physical symptoms as well their psychosocial and spiritual needs. In addition to receiving medical care, this approach would allow patients to express their concerns, worries and existential anxieties and receive help in coping with and finding meaning in their experiences. ${ }^{19}$ This may prevent their spiritual distress from contributing to greater service use and reduce the economic burden of care on families.

\section{Strength and limitations of the study}

This is the first study to report the spiritual issues of patients living and dying of HF in Kenya. With a few exceptions past studies exploring the role of spirituality in health and illness have mostly relied on objective measurements. ${ }^{46}$ In contrast, our longitudinal qualitative approach allows for dynamic and in-depth personal accounts of ways in which spirituality shapes patients' experiences. Patients were allowed to use their own words to explain how their beliefs not only helped them cope but at times added to their distress. The longitudinal nature of this study allowed us to build trusting relationships where patients felt at ease to disclose sensitive information. ${ }^{25} 26$ The result, our approach was a rich and complex narrative in which patients described the role of spirituality in their illness experience. While 
attempts were made to recruit participants from various sociodemographic, ethnic and religious groups living in Central Kenya, it is unknown to what extent these findings may be applicable in other settings.

\section{CONCLUSION}

Spirituality for those living with HF in Kenya may be a source of comfort but also lead to distress. Patients' beliefs may mask underlying anxiety which may trigger multidimensional distress and lead to poorer health outcomes. This may increase health service use and plunge households into worsening poverty. A patient-centred holistic approach to care may be beneficial in identifying patients' spiritual concerns and offering support to improve their quality of care and quality of life.

\section{Handling editor Seye Abimbola}

Contributors KNK, SAM and LG developed and designed this study. KNK was the primary researcher. KNK collected all the data and conducted initial data analysis. All authors contributed to data interpretation. KNK prepared the initial manuscript and all authors contributed to its final version.

Funding This study was supported by the University of Nairobi PhD training programme.

\section{Competing interests None declared.}

Ethics approval Ethics approval was granted by the Kenyatta National Hospital/University of Nairobi Ethics and Research Committee (P469/07/2014) and the Ethics Review Group at the University of Edinburgh.

Provenance and peer review Not commissioned; externally peer reviewed.

Data sharing statement No additional data are available.

Open Access This is an Open Access article distributed in accordance with the Creative Commons Attribution Non Commercial (CC BY-NC 4.0) license, which permits others to distribute, remix, adapt, build upon this work noncommercially, and license their derivative works on different terms, provided the original work is properly cited and the use is non-commercial. See: http:// creativecommons.org/licenses/by-nc/4.0/

\section{REFERENCES}

1. Koenig HG. Religion and medicine I: historical background and reasons for separation. Int J Psychiatry Med 2000;30:385-98.

2. Monod S, Brennan M, Rochat E, et al. Instruments measuring spirituality in clinical research: a systematic review. J Gen Intern Med 2011;26:1345-57.

3. The World Health Organization quality of life assessment (WHOQOL): development and general psychometric properties. Soc Sci Med 1998;46:1569-85.

4. Sulmasy DP. A biopsychosocial-spiritual model for the care of patients at the end of life. Gerontologist 2002;42(Spec No 3):24-33.

5. World Health Organisation. WHO Definition of Palliative Care. http:// www.who.int/cancer/palliative/definition/en/ (accessed $20 \mathrm{Jul}$ 2016).

6. Fitzsimons D, Mullan D, Wilson JS, et al. The challenge of patients' unmet palliative care needs in the final stages of chronic illness. Palliat Med 2007;21:313-22.

7. Murray SA, Kendall M, Boyd K, et al. Exploring the spiritual needs of people dying of lung cancer or heart failure: a prospective qualitative interview study of patients and their carers. Palliat Med 2004;18:39-45.

8. Murray SA, Kendall M, Grant E, et al. Patterns of social, psychological, and spiritual decline toward the end of life in lung cancer and heart failure. J Pain Symptom Manage 2007;34:393-402.

9. Harding R, Selman L, Beynon T, et al. Meeting the communication and information needs of chronic heart failure patients. $J$ Pain Symptom Manage 2008;36:149-56.
10. Boyd KJ, Murray SA, Kendall M, et al. Living with advanced heart failure: a prospective, community based study of patients and their carers. Eur J Heart Fail 2004;6:585-91.

11. Westlake C, Dracup K. Role of spirituality in adjustment of patients with advanced heart failure. Prog Cardiovasc Nurs 2001;16:119-25.

12. Beery TA, Baas LS, Fowler C, et al. Spirituality in persons with heart failure. J Holist Nurs 2002;20:5-25; quiz 26-30.

13. Bekelman DB, Dy SM, Becker DM, et al. Spiritual well-being and depression in patients with heart failure. J Gen Intern Med 2007;22:470-7.

14. Koenig HG. Religion, spirituality, and health: the research and clinical implications. ISRN Psychiatry 2012;2012:278730.

15. Alvarez JS, Goldraich LA, Nunes AH, et al. Association between spirituality and adherence to management in outpatients with heart failure. Arq Bras Cardiol 2016;106:491-501.

16. Dalal S, Beunza JJ, Volmink J, et al. Non-communicable diseases in sub-Saharan Africa: what we know now. Int J Epidemiol 2011;40:885-901.

17. Kimani K, Namukwaya E, Grant L, et al. What is known about heart failure in sub-Saharan Africa: a scoping review of the English literature. BMJ Support Palliat Care 2016;

18. Samb B, Desai N, Nishtar S, et al. Prevention and management of chronic disease: a litmus test for health-systems strengthening in low-income and middle-income countries. Lancet 2010;376:1785-97.

19. Grant E, Murray SA, Kendall M, et al. Spiritual issues and needs: perspectives from patients with advanced cancer and nonmalignant disease. A qualitative study. Palliat Support Care 2004;2:371-8.

20. Takyi BK. Religion and women's health in Ghana: insights into HIV/ AIDs preventive and protective behavior. Soc Sci Med 2003;56:1221-34.

21. Trinitapoli J, Regnerus MD. Religion and HIV risk behaviors among married men: initial results from a study in rural sub-Saharan Africa. J Sci Study Relig 2006;45:505-28.

22. Mayo R, Hunter A. Fatalism toward breast cancer among the women of Ghana. Healthcare Women Int 2003;24:608-16.

23. Hill PC, Pargament $\mathrm{KI}$, Hood RW, et al. Conceptualizing religion and spirituality: points of commonality, points of departure. J Theory Soc Behav 2000;30:51-77.

24. Puchalski CM, Vitillo R, Hull SK, et al. Improving the spiritual dimension of whole person care: reaching national and international consensus. J Palliat Med 2014;17:642-56.

25. Kimbell B, Kendall M, Boyd K, et al. Living and dying with liver failure: a serial interview study. BMJ Support Palliat Care 2013;3:124.

26. Murray SA, Boyd K, Kendall M, et al. Dying of lung cancer or cardiac failure: prospective qualitative interview study of patients and their carers in the community. BMJ 2002;325:929.

27. Braun V, Clarke V. Successful qualitative research: a practical guide for beginners. Sage, 2013.

28. Bhaskar R. Reclaiming reality: a critical introduction to contemporary philosophy. Taylor \& Francis, 2010.

29. Maxwell JA. Qualitative research design: an interactive approach Sage, 2012.

30. Damasceno A, Mayosi BM, Sani M, et al. The causes, treatment and outcome of acute heart failure in 1006 Africans from 9 countries: results of the sub-Saharan Africa survey of heart failure. Arch Intern Med 2012;172:1386-94.

31. Worth A, Irshad T, Bhopal R, et al. Vulnerability and access to care for south Asian Sikh and Muslim patients with life limiting illness in Scotland: prospective longitudinal qualitative study. $B M J$ 2009;338:526-30.

32. Mason M. Sample size and saturation in PhD studies using qualitative interviews. Forum Qual Soc Res 2010;11. http://www. qualitativeresearch.net/index.php/fqs/article/view/1428/3027 (accessed 15 Jul 2016).

33. Braun V, Clarke V. Using thematic analysis in psychology. Qual Res Psychol 2006;3:77-101.

34. Hall HR, Roussel LA. Evidence-based practice. Jones \& Bartlett Publishers, 2012.

35. Tong A, Sainsbury P, Craig J. Consolidated criteria for reporting qualitative research (COREQ): a 32-item checklist for interviews and focus groups. Int J Qual Healthcare 2007;19:349-57.

36. 'Namukwaya E, Murray S, Leng M, et al. Experience of living with advanced heart failure in Uganda. BMJ Support Palliat Care 2014;4 (Suppl 1):A82.

37. Selman L, Brighton L, Harding R. Palliative and supportive care needs of heart failure patients in Africa: a review of recent developments. Curr Opin Support Palliat Care 2015;9:20-5. 
38. Ross L, Austin J. Spiritual needs and spiritual support preferences of people with end-stage heart failure and their carers: implications for nurse managers. J Nurs Manag 2015;23:87-95.

39. Fitchett G, Murphy PE, Kim J, et al. Religious struggle: prevalence, correlates and mental health risks in diabetic, congestive heart failure, and oncology patients. Int J Psychiatry Med 2004;34: 179-96.

40. Moser DK, Heo S, Lee KS, et al. 'It could be worse...lot's worse!' Why health-related quality of life is better in older compared with younger individuals with heart failure. Age Ageing 2013;42: 626-32.

41. Mbiti JS. Introduction to African religion. Waveland Press, 2015.
42. Murray SA, Grant E, Grant A, et al. Dying from cancer in developed and developing countries: lessons from two qualitative interview studies of patients and their carers. BMJ 2003;326:368.

43. Blinderman CD, Cherny NI. Existential issues do not necessarily result in existential suffering: lessons from cancer patients in Israel. Palliat Med 2005;19:371-80.

44. World Health Organisation. Preventing chronic diseases: a vital investment. WHO Global Report, 2005.

45. Hunt S. 'Winning Ways': globalisation and the impact of the health and wealth Gospel. J Contemp Relig 2000;15:331-47.

46. Ellison CG. Religious involvement and subjective well-being. $J$ Health Soc Behav 1991;32:80-99. 